\title{
Assessing Students Engagement in an Online Student Question-Generation Activity towards Their Learning Motivation
}

\author{
Masturah Sabri, Faten Khalida Khalid, and Liew Khe Li
}

\begin{abstract}
The purpose of this study is to look into and develop a better understanding on how students are motivated to learn through the tasks of creating their own learning content. In this study, students are exposed to question-generation activity, which employed Peer Wise as a platform - a web-based application that allows students to create, answer and share multiple choice questions. A self-report instrument were used to measure students motivational construct of intrinsic goal orientation, extrinsic goal orientation, perception of task value and control of learning beliefs and self- efficacy for learning and performance with the students' level of engagement in the question-generation activity. The instrument was adapted from Motivated Strategies for Learning Questionnaire (MSLQ). T-test results indicated that there were significant differences between most-active and least-active contributors in the component of intrinsic goal orientation, perception of task value, and control of learning beliefs; whereby, most-active contributors tends to develop higher motivation drive in the mentioned motivation component. Correlation analysis revealed that the strongest correlation is between intrinsic motivation and the perception of task value between the most-active contributors. The result further revealed that most-active contributors valued the task given, which is to create, share and answer multiple-choice online as important and beneficial as compared to least-active contributors.
\end{abstract}

Index Terms-Student-generated question, PeerWise, learning motivation, MSLQ.

\section{INTRODUCTION}

Approaches to learning are among the factors that may influence students' academic achievement, and previous studies have found that the variation in ways students react and approach their learning has contributed to their learning outcomes. Instructors in higher education have come up with a variety of activities to incorporate theories and pedagogies that are built to enhance learning and achievement.

One way to heightened output in learning is through activities and tasks introduced in classroom; and, given the rapid development of new technology, instructors are challenged to experiment with different methods and approaches to maximize learning especially by integrating the ever advancing technology.

While there continues to be significant discussion on the

Manuscript received January 13, 2016; revised March 10, 2016. This work was supported in part by Universiti Malaysia Perlis under Short Term Grant 9009-00035.

The authors are with the Center for International Languages, Universiti Malaysia Perlis, Perlis, Malaysia (e-mail: masturahsabri@unimap.edu.my). advantages of integrating technology in classroom primarily to enhance self-regulated and student-centred learning, studies also reported that technology alone are unable to ensure students' success in learning, especially when it comes to other factors that might influence the learning process. Previous research, especially on language learning, has clearly evidenced that one of the principal determinants of success in learning is motivational factor [1].

Many activities incorporated in higher education teaching and learning are based on theories or pedagogies that support motivational factor as one of the important element in success of students' learning. Tasks and activities such as problem-solving, students' question-generation, peer-assessment, peer-feedback and other tasks that enhance cognitive and meta-cognitive values are one of the preferred learning activities in higher education. Recent evidence indicates that by paying insufficient attention to motivation, even high-cognitive activities such as problem-based learning might not be able to boost learning among students [2].

The contribution of students to their learning process is not a new trend. Students' online contributions of content and ideas by generating own questions to academic discourse have been significantly enhanced over the last years [3]-[7]. At their best, technological innovations can contribute to the growth of learners' interest and motivation; provide students with interaction opportunities and feedback. Furthermore, students, as well as lecturers are demonstrating positive attitudes and preference towards technology integration in their learning experience [8]-[11].

The range of readily available and easily access interactive technologies provide lecturers a vast selection for delivering content using a diverse learning approaches and pedagogies. The new generation of web 2.0 technologies are able to facilitate online class collaboration and allow students to create and share content in a variety of forms [12] and further allowing students to be actively engaged and in control of their learning process [13].

The development of modern technology has created numerous platforms to aid in configuring large-scale learning environments suited to the efficient management of students' contribution such as student-generated questions [4], [7]. The contributing student pedagogy (CSP) is among the pedagogies that encourage students to contribute to their learning process and to appreciate the contribution of others [14] as students are said to perform better during "high-cognitive tasks" such as learning, problem-solving and thinking creatively, when they are intrinsically motivated to complete a task [15]. 
Unfortunately, a problematic and common assumption among educational researchers is that students will be automatically engaged to learning once they are exposed to authentic or problem-solving activities [16]-[18] such as question-generation. Studies shows that this is not always the case, due to factors such as poor relation among peers [19] poor elicitation and maintenance of interest [20] as well as weakened intrinsic motivations due to extrinsic motivators [15].

Many existing literature on student-generated content (SGC) has framed the benefits associated with student-question generation such as on the impact on students learning performance and engagement [4]-[7], [12], [21]-[24] but, very few studies has looked into the added effects derived from the student question-generation activities such as anxiety and motivation towards students learning in higher education.

It is crucial to develop a better understanding of how students are motivated to learn during certain activities or tasks, and how the tasks impact their motivation towards learning. Therefore, this study intended to look into the effects of engaging students in question-generation activities have on their learning motivation through an online learning system.

\section{LITERATURE REVIEW}

\section{A. Student Question-Generation}

It is widely recognised that the activity of creating questions promotes students' understanding of course materials; as it involved higher order cognitive skills and has been linked to self-directed learning and, therefore, will improve conceptual understanding [25]. For students to be able to generate questions, it require not just merely a simple recollection of what they have learnt, it goes beyond just revising the key learning outcomes and core subject materials; that it actually engaged them to reflect on their learning [26], [27]. It also let students practice on their metacognition, an important mechanism to foster and monitor comprehension [28]. It also has been argued that a deeper understanding can be achieved by having students create, pose and answer questions [29].

As to encourage deep and critical thinking, it is far more demanding to generate both correct and incorrect reasoning and answers to a question (as in creating multiple-choice items), rather than just attempting to find a solution to a question or an issue.

Question generation by students may also be used to support constructive alignment between instruction, teaching and learning as it can help instructors to assess their teaching competency and instructions given by looking at students' question generation ability.

\section{B. Student-Generated Multiple-Choice Questions}

Occasionally, MCQs are still viewed as having limited applicability as it does not require students to provide reasoning; whereby, students may just pick any of the choices given as answer and still have the chance to get the question right. However, despite the small percentage to still get the answer right by guessing, a study by [30] highlighted the importance of not just the questions themselves, but also the context in which the MCQs were deployed within modules to promote the development of self-directed learning. [30] also stressed that choosing to have MCQs as a type of assessment; even those MCQs that are developed by students can promote self-regulation and encourage student motivation on the task given.

This may be due to the challenging task of creating good multiple-choice questions, as is not straightforward. Students would have to generate an appropriate question stem, and then come up with some suitable alternatives that contain several distractors. The generation of alternatives will probably be the most challenging; as it is not an easy task to create a few distractors that are close to the answer without revealing the correct answer. By making students generate their own MCQs, it is useful not only for testing students' knowledge on the issues [22] but also in promoting deep learning [31] as students are to perform better when involved with 'high cognitive' tasks of thinking creatively [32], such as during the development of possible distractors for the alternatives in MCQ generation.

However, there are also issues highlighted in making students creating their MCQs. A study done by [21] gives the impression that students' require external motivation in terms of reminder or marks to support students' question generation. Also, issue related to the quality of the created question bank [22] are brought up in the literature. A study from [33] has as well highlighted a few concerns from the teachers' standpoint; among them are: the quality of questions that will be available, the evidence of learning benefits and the students' perception of activity value when engaging the question generation activity with PeerWise - an online tool that allow students to create and share multiple-choice questions online. Due to this, the literature suggests that PeerWise to be widely adopted across courses and education field to strengthen findings in supporting the use of PeerWise in higher education.

In short, involving students in creating their own multiple-choice questions offers a better deal than just merely attempting to answer teacher-provided questions; as they are beneficial in promoting in-depth learning [31], fostering critical thinking [32] and encouraging self-directed learning [30].

\section{PeerWise System}

The range of new media-rich technologies has provided teachers of higher education various options for delivering content using pedagogically diverse approaches [34]. Students, in general, are demonstrating positive attitude and preference towards technology integration in their learning experience [8], [10], [35]. The emerging scenario has developed various learning online tools such as such as ExamNet, PeerWise, QuARKS, CodeWrite, and StudySieve. Each online tool has been drawn up by employing a diverse learning pedagogies and theories to suit the learners' need.

PeerWise is one of the learning systems that support students' interaction and collaboration while learning [21]. It provides a platform for teachers and students to build a repository of multiple-choice questions created students. PeerWise is a user-friendly tool that requires no introductory 
course or short course for students to effectively make use of it. To start, students will need to register themselves to create their individual username and password by using a class code that will link them directly to their course page. They can start creating question, (or answering if there are already questions posted up by their peers), on the system. To create new question is straightforward. The student author will create question and providing the correct answer as well as distractors to the question. The author is also required to provide an explanation to the question's answer as reference purposes for the other students.

PeerWise is created to be used in any and multiple courses and not just tied to a particular field. It is an online tool that does not require specific presence of the academic staff to administer the question generation by students; rather, learners are free to provide feedbacks to their peers by leaving comments if needed.

\section{Student Learning Motivation}

Motivation refers to the 'choices individuals make regarding their experiences and /or goals they will seek and the additional amount of effort they will expand in these experiences' [36].

For the past decades, many studies have focused on topic of the learning motivations of university students [37], [38] as well as study on the relationships between students' internal motivations and learning environment. Study by [15] also focuses on intrinsic motivation in learners, where learners are said to perform better during "high-cognitive tasks" such as problem-solving and thinking creatively, when they are intrinsically motivated to complete a task. Intrinsic motivation may encourage learners to contribute to the learning process without the guidance and direction of the teaching staff [39]. The studies mentioned also argued that the instructor does play a significant role in creating an encouraging environment to boost learning motivation.

As the contribution of students to the learning process is not a new phenomenon, where academic motivation is seen as a powerful factor in getting them more interested in learning [40]; the success of student question generation activities can be maximized if the instructor has a better understanding of how students are motivated to learn by investigating on how motivation theories explain students motivation during those tasks [41], [42]. And by looking at how the activity of developing student-generated questions and answering student-generated questions, impact their motivations to learn [14].

From a study by [38], they revealed that students' motivation change from course to course, depending on factors such as; their interest in the course, efficacy for performing in a course, their goals or even the value beliefs they have for the particular course. Students' learning strategies may also vary, depending on the nature of the course. It is perceived that students with higher motivation level in learning would generally perform better, has higher involvement and were more efficient in performing task give; that, therefore, will lead to them achieving better grades than those who are less motivated in their study.

As educators, it is crucial to understand that we must know whether the teaching and learning theories and experiences that we brought to our classroom are creating a motivating environment or not. The environment that is created for the students is essential as it helps to determine the rate of success.

\section{Methodology}

\section{A. Research Design}

The focus of this study is to look into the effects of engaging students in question generation activities have on their learning motivation through an online learning system called PeerWise. In this study, PeerWise was introduced to 1 class of students registered in a 'technical English communication' course. Teaching on this subject is conducted primarily by lectures and a few sessions of group discussions. Assessment for this course is done using in-class mid-term test, a group project report totaling of $50 \%$ and a final exam which worth another $50 \%$.

The study was conducted for eight weeks, from the beginning of the semester right to a week after their mid-term exam; where a survey was distributed after they have been exposed to the question generation activities of writing, sharing and answering multiple-choice questions through the Peerwise platform. Students were allocated the first eight weeks of their semester to use Peerwise to contribute, and answer their multiple choice questions. They were asked to provide a minimum of one question, answer a minimum of 5 questions posted by their friends and rate, write critique or comments on the questions of others if they wish.

During the first two weeks of the semester, students are briefed for around 30 minutes about the online system of Peerwise in each classes, where they were given a week to register and familiarize themselves to the system. No formal training in the writing of good multiple choice questions was offered; however, a power point slides containing guidelines on how to create good multiple choice questions was prepared for the students. Besides, a good quality example question was also showed to the students to set a bar for creativity and quality in creating multiple-choice questions.

There was also no specific training on the general use of the systems, only a brief guideline on how to register, along with the course code needed to enter the system was provided. The training is viewed to be unnecessary as the students are experienced user of the internet and the Peerwise system is user-friendly. Students are required to create questions based on any of the lectures delivered in class or from the theoretical chapters in their course textbook. Since the purpose of this study is to look into their motivation drive; to eliminate any possible distractor, of mainly extrinsic motivational elements, no marks were allocated for students participating in the activity.

Academic staff involvement was passive after introducing the activity to the students during the first week and guiding them to write their own multiple choice question in the second week of the class. This is to generate a student-led peer-learning environment for the task. Students may assess the system anywhere and anytime they wish within the time-frame of 8 weeks. This was a deliberate policy so that students can take full ownership of their material and also a 
measure taken by the researcher to avoid any influence of engaging to the system because of the pressure of teacher's presence and constant reminder.

After being exposed to the question generation activities of writing, sharing and answering multiple-choice questions through Peerwise for 8 weeks, a survey is given in the classroom to look into their motivational drive.

\section{B. Sample}

A number of 54 students participated in this study. Of the 54 students, $46(85.2 \%)$ of them are female, and the remaining of $8(14.8 \%)$ are male students. The participants are mostly second-year undergraduate students in one of a public university in Malaysia. All the participants of this study enrolled into a 'technical English communication' class. Students chosen for this study have not been exposed to any question-generation activities in other courses before.

\section{Research Instrument}

A paper-based survey is conducted after students were exposed to the question generation activities for 8 weeks. In order to measure the motivational drive of the students after being exposed to the activities, an instrument called the Motivated Strategies for Learning Questionnaire (MSLQ) is employed. MSLQ is a widely used, likert-type, self-report instrument designed in two parts, which can be used separately [43]. It is designed to assess students' motivation and, or study skills within a given course.

One part of the construct is to be used to evaluate tertiary level students' motivational orientations and the second part is used to look into the students' employment of learning strategies. In this study, only one part of the instrument will be utilized; which is the motivation section. The motivation section comprises of 6 sub-scales which items designed to assess students' goals and value beliefs for a course, their beliefs about their skills to succeed in a course and their anxiety about tests in a course. Whereas the learning strategy section addresses on 9 subscales with items regarding students use of different cognitive and meta-cognitive strategies as well as management of various resources, such as study management and effort regulation.

For the purpose of this study, five motivational sub-scales, of the altogether 15 subscales; are chosen as it contained items that are more pertinent to this study. The listing is presented in Table I.

\begin{tabular}{lc}
\multicolumn{2}{c}{ TABLE I: LiSTING OF MotIVATIONAL SUB-SCALES ITEMS } \\
\hline Motivation Scales of the MSLQ & Number of items \\
\hline 1.Intrinsic Goal Orientation & 4 \\
2.Extrinsic Goal Orientation & 4 \\
3. Task Value & 6 \\
4. Control of learning beliefs & 4 \\
5. Self- Efficacy for Learning and & 8 \\
Performance & \\
\hline
\end{tabular}

Cronbach coefficient alpha reliabilities for the items used in the study (list is presented in Table II) were .74 for intrinsic goal orientation, .62 for extrinsic goal orientation, .90 for task value, .68 for control of learning beliefs subscale, and last.93 for self-efficacy subscales. The majority of the Cronbach alpha for most of the subscales were relatively high and had good internal reliability as it is greater than .70 [44].

\section{DATA ANALYSIS}

The students who participated in this study are divided into 2 categories, based on the quartiles of most-active (MA) and least-active (LA) contributors. The divisions to these categories are calculated based on their scores obtained from Peerwise system, by looking at the mean score of their contribution. The mean scores were then used to separate them into 2 quartiles; the most active, and least active. Those who obtained a mean of 3.1 and more are most-active contributors and those with a mean of 3.0and less are least-active contributors, based on the minimum requirement of authoring one question and answering a minimum of 5 questions.

\section{A. Pattern Usage of Peerwise}

Table II displays the students' distribution based on their engagement in PeerWise, calculated using the mean score of their contribution.

TABLE II: Students’ Distribution BASEd on TheIr MEAN ENGAGEMENT

\begin{tabular}{llll}
\multicolumn{3}{c}{ IN PEERWISE } \\
\hline \hline Most & Frequency & Percentage $(\%)$ \\
(MA) & 19 & 35.2 \\
Least Active (LA) & 35 & 64.8 \\
& Total & 54 & 100 \\
\hline \hline
\end{tabular}

Data from PeerWise system was accessed and downloaded at the end of the study duration of 8 weeks. The pattern usage of PeerWise by students across 8 weeks is reported in this section. Tables III and IV shows a breakdown of students' contribution based on the categories of most-active and least-active.

TABLE III: BREAKDOWn OF StUdENTS' CONTRIBUTION: MOST-ACTIVE

\begin{tabular}{lll}
\multicolumn{3}{c}{ CONTRIBUTORS } \\
\hline \hline Metric & Total & Average per student \\
\hline Questions written & 33 & 1.7 (1 required) \\
Questions answered & 301 & 15.8 (5 required) \\
\hline \hline
\end{tabular}

TABLE IV: BREAKDOWN OF STUDENTS' CONTRIBUTION: LEAST-ACTIVE CONTRIBUTORS

\begin{tabular}{lll}
\hline \hline Metric & Total & Average per student \\
\hline Questions written & 46 & $1.3 \quad(1$ required $)$ \\
\hline Questions answered & 14 & $0.4 \quad(5$ required $)$ \\
\hline \hline
\end{tabular}

Findings in Table III show a breakdown of the most-active students' contribution. Overall, the most-active students have written an average of 1.7 questions per student and have answered an average of 15.8 questions over 5 questions that are required, that makes the total of answered questions is 301 questions. All the most-active students contributed beyond than the expected contribution. Table IV shows a breakdown of the least-active students' contribution. On the whole, least-active students have written an average of 1.3 questions per student and have answered an average of 0.4 questions over 5 questions that are required. This shows that, least-active students have written, on average more questions than expected. However, for the number of question answered by them, they contributed far less than the expected amount required. 
Table V and Table VI show the distribution of question contribution by the students. Data shows that no students have contributed more than 2 questions. However, the majority $(51.9 \%)$ has authored more than the required number of questions. Based on the distribution of question answered, in general, $32.1 \%$ answered less than the required number, which is 5 questions, the majority (57.2\%) answered in the range of 5 to 20 questions. The remaining $3.6 \%$ and $7.1 \%$ answered in the range of 21-40 questions and more than 40 questions respectively.

\begin{tabular}{lc}
\multicolumn{2}{c}{ TABLE V: DISTRIBUTION OF QUESTION WRITTEN } \\
\hline \hline No. of questions written & $\%$ \\
\hline 1 & 48.1 \\
2 & 51.9
\end{tabular}

\begin{tabular}{ll}
\multicolumn{2}{c}{ TABLE VI: DISTRIBUTION OF QUESTION ANSWERED } \\
\hline \hline No. of questions answered & $\%$ \\
\hline$<5$ & 32.1 \\
$5-20$ & 57.2 \\
$21-40$ & 3.6 \\
$>40$ & 7.1 \\
\hline \hline
\end{tabular}

\section{B. Differences between Motivation on Active and Least Active Students}

An independent sample t-test was employed to look into the difference in the mean of intrinsic goal orientation, extrinsic goal orientation, task value, control of learning beliefs, selfefficacy for learning and performance between most-active(MA) and least active (LA) contributors.

The t-test result shows that there were significant differences between most-active and least active contributors in the component of intrinsic goal orientation $(p$-value $=0.013$ $<0.05)$, task value, ( $p$-value $=0.000<0.05)$, and control of learning beliefs $(p$-value $=0.000<0.05$ ). The mean values indicate that most-active contributors have higher intrinsic goal orientation $(M=4.8241)$, task value orientation $(M=5.8421)$, control of learning beliefs $(M=5.9737)$ than least-active contributors of question generation activity. The result also revealed that there was no statistically difference between most-active and least-active contributors in the subscales of extrinsic goal orientation $(p$-value $=0.114>0.05)$ and self-efficacy $(p$-value $=0.489>0.05)$.

From the findings, the motivational components with statistically significant differences (intrinsic goal orientation, task value and control of learning beliefs) were further look into the items that are present in the sub-scales.

\section{1) Intrinsic goal orientation}

Goal orientation refers to learners' general goals or orientation to the course. Intrinsic goal orientation looks into the degree of which students perceive themselves to be participating in a task. Learners with high intrinsic motivation are more determined and goal oriented.

The result presented in Table VII shows that for the items to look into students' intrinsic motivation while engaging with the question-generation activities, item one to three are statistically significant. Item 1 shows that MA students perceived that they are participating in the question-generation activity for reasons such as challenge ( $p$-value $=0.035<0.05, M=4.89)$, curiosity towards the given task $(p$-value $=0.014<0.05, M=4.89)$, and to master the content $(p$-value $=0.019<0.05, M=5.11)$. However, the last item, item 4 , shows no different in opinion between most active and least active contributors.

TABLE VII: T-TEST OF INTRINSIC GOAL ORIENTATION BETWEEN MOST ACTIVE AND LEAST ACTIVE STUDENTS

\begin{tabular}{|c|c|c|c|c|}
\hline Item & $\begin{array}{l}\text { Mean }(S D) \\
\text { Most } \\
\text { active } \\
(\mathrm{N}=19)\end{array}$ & $\begin{array}{l}\text { Least } \\
\text { Active } \\
(\mathrm{N}=35)\end{array}$ & $t$ & sig \\
\hline $\begin{array}{l}\text { 1.In a class like this, I } \\
\text { prefer course } \\
\text { material that really } \\
\text { challenges me so I } \\
\text { can learn new } \\
\text { things. }\end{array}$ & $\begin{array}{l}4.89 \\
(0.875)\end{array}$ & $\begin{array}{l}4.34 \\
(0.906)\end{array}$ & -2.163 & 0.035 \\
\hline $\begin{array}{l}\text { 2. In a class like this, I } \\
\text { prefer course } \\
\text { material that } \\
\text { arouses my } \\
\text { curiosity, even if it } \\
\text { is difficult to learn. }\end{array}$ & $\begin{array}{l}4.89 \\
(0.994)\end{array}$ & $\begin{array}{l}4.26 \\
(0.817)\end{array}$ & -2.536 & 0.014 \\
\hline $\begin{array}{l}\text { 3. The most satisfying } \\
\text { thing for me in this } \\
\text { course is trying to } \\
\text { understand the } \\
\text { content as } \\
\text { thoroughly as } \\
\text { possible. }\end{array}$ & $\begin{array}{l}5.11 \\
(1.049)\end{array}$ & $\begin{array}{l}4.34 \\
(1.136)\end{array}$ & -2.418 & 0.019 \\
\hline $\begin{array}{l}\text { 4. When I have } \\
\text { opportunity in this } \\
\text { class, I choose } \\
\text { course assignments } \\
\text { that I can learn from } \\
\text { even if they don't } \\
\text { guarantee a good } \\
\text { grade. }\end{array}$ & $\begin{array}{l}4.47 \\
(0.964)\end{array}$ & $\begin{array}{l}4.60 \\
(0.914)\end{array}$ & 0.476 & 0.636 \\
\hline
\end{tabular}

2) Student perception of task value

TABLE VIII: T-TEST OF TASK VALUE BETWEEN Most ACTIVE AND LEAST ACTIVE STUDENTS

\begin{tabular}{|c|c|c|c|c|}
\hline \multirow[t]{2}{*}{ Item } & \multicolumn{4}{|c|}{ Mean (SD) } \\
\hline & $\begin{array}{l}\text { Most } \\
\text { Active }\end{array}$ & $\begin{array}{l}\text { Least } \\
\text { Active }\end{array}$ & $t$ & sig \\
\hline $\begin{array}{l}\text { 1.It is important for me to } \\
\text { learn the course material } \\
\text { in this class }\end{array}$ & $\begin{array}{l}6.42 \\
(0.838)\end{array}$ & $\begin{array}{l}4.89 \\
(1.105)\end{array}$ & -5.279 & 0.000 \\
\hline $\begin{array}{l}\text { 2. Understanding the } \\
\text { subject matter of this } \\
\text { course is very } \\
\text { important to me }\end{array}$ & $\begin{array}{l}6.16 \\
(0.898)\end{array}$ & $\begin{array}{l}5.71 \\
(0.825)\end{array}$ & -1.829 & 0.073 \\
\hline $\begin{array}{l}\text { 3.I think I will be able to } \\
\text { use what I learn in } \\
\text { this course in other } \\
\text { courses. }\end{array}$ & $\begin{array}{l}5.21 \\
(1.084)\end{array}$ & $\begin{array}{l}4.63 \\
(0.910)\end{array}$ & -2.097 & 0.041 \\
\hline $\begin{array}{l}\text { 4.I think the course } \\
\text { material in this class } \\
\text { is useful for me to } \\
\text { learn. }\end{array}$ & $\begin{array}{l}6.26 \\
(0.452)\end{array}$ & $\begin{array}{l}5.86 \\
(0.912)\end{array}$ & -1.817 & 0.075 \\
\hline $\begin{array}{l}\text { 5.I like the subject matter } \\
\text { of this course. }\end{array}$ & $\begin{array}{l}5.42 \\
(0.961)\end{array}$ & $\begin{array}{l}4.51 \\
(0.742)\end{array}$ & -3.858 & 0.000 \\
\hline $\begin{array}{l}\text { 6.I am very interested in } \\
\text { the content area of } \\
\text { this course. }\end{array}$ & $\begin{array}{l}5.58 \\
(1.121)\end{array}$ & $\begin{array}{l}4.20 \\
(1.052)\end{array}$ & -4.496 & 0.000 \\
\hline
\end{tabular}

Task value refers to students' evaluation on the importance 
of the task. It refers to the perception of how interesting, how important and how useful a task is. From the task value component, 4 out of 6 items shows a statistically significant difference in opinion for MA and LA contributors (see Table VIII).

Item 1 demonstrates that active contributors perceived that learning the course material is important ( $p$-value $=0.000<$ $0.05, M=6.42$ ). Item 3 expressed that active contributors (with mean value of $M=6.42$ ) thinks that questionsgeneration activity will benefit them in other courses $(p$-value $=0.041<0.05)$. Item 5 and 6 illustrate that most-active contributors (mean value of $M=6.42$ ) show liking towards the subject matter of the course ( $p$-value $=0.000<$ $0.05)$; and, are interested with the content of the course ( $p$-value $=0.000<0.05, M=5.58)$; as compared to least-active contributors (mean value of $M=4.20$ ).

\section{3) Control of learning beliefs}

Control of learning beliefs refer to students' belief that their effort to learn will result in positive outcomes. They trust that the outcomes of their learning, positive or negative depends on their learning behaviour, not owing to external factors such as the teacher. There are 4 items in this component, from the analysis, 3 of the items reveal that there are statistically difference in beliefs between most active and least active contributors in the question-generation activity. Item 1 and 2 shows that active students have a belief that they will only able to learn the course material only if they studied appropriately $(p$-value $=0.000<0.05, M=6.00)$ and tried hard enough $(p$-value $=0.001<0.05, M=5.95)$, as compared to the least active students $(M=4.74, M=4.86)$. Item 3 shows that active students feels that it is their responsibility if they do not learn the materials used in the course ( $p$-value $=0.028<0.05$, $M=5.84$ ). The last items, however, did not differ significantly in terms of beliefs between MA and LA contributors in the question-generation activity (see Table IX).

TABLE IX: T-TEST OF TASK VALUE BETWEEN MosT ACTIVE AND LEAST ACTIVE STUDENTS

\begin{tabular}{|c|c|c|c|c|}
\hline \multirow[b]{2}{*}{ Item } & \multicolumn{4}{|c|}{ Mean (SD) } \\
\hline & $\begin{array}{l}\text { Most } \\
\text { Active }\end{array}$ & $\begin{array}{l}\text { Least } \\
\text { Active }\end{array}$ & $t$ & sig \\
\hline $\begin{array}{l}\text { 1.If I study in appropriate } \\
\text { ways, then I will be } \\
\text { able to learn the } \\
\text { material in this } \\
\text { course }\end{array}$ & $\begin{array}{l}6.00 \\
(1.000)\end{array}$ & $\begin{array}{l}4.74 \\
(1.120)\end{array}$ & -4.084 & 0.000 \\
\hline $\begin{array}{l}\text { 2.If I try hard enough, } \\
\text { then I will } \\
\text { understand the } \\
\text { course material. }\end{array}$ & $\begin{array}{l}5.95 \\
(1.129)\end{array}$ & $\begin{array}{l}4.86 \\
(1.089)\end{array}$ & -3.469 & 0.001 \\
\hline $\begin{array}{l}\text { 3.It is my own fault if I } \\
\text { don't learn the } \\
\text { material in this } \\
\text { course. }\end{array}$ & $\begin{array}{l}5.84 \\
(1.119)\end{array}$ & $\begin{array}{l}5.11 \\
(1.132)\end{array}$ & -2.266 & 0.028 \\
\hline $\begin{array}{l}\text { 4.If I don't understand } \\
\text { the course material, } \\
\text { it is because I didn't } \\
\text { try hard enough. }\end{array}$ & $\begin{array}{l}6.11 \\
(0.459)\end{array}$ & $\begin{array}{l}5.71 \\
(0.860)\end{array}$ & -1.839 & 0.072 \\
\hline
\end{tabular}

As the result revealed that there was no statistically difference between most-active and least-active contributors in the subscales of extrinsic goal orientation $(p$-value $=0.114>$ $0.05)$ and self-efficacy $(p$-value $=0.489>0.05)$, the detailed of the items were not looked into.

\section{Relationship between Motivation Components and}

Students' Engagement in the Question-Generation Activity

Person Correlation was employed to explore the correlation matrix of the most-active and least active contributors across 5 motivational subscales of intrinsic goal orientation, extrinsic goal orientation, task value, control of learning beliefs, self- efficacy for learning and performance. Results were presented in Section I looking into the relationship between motivation sub-scales of most-active contributors and Section II presents the result for the least-active contributors.

\section{1) Relationship between motivation sub-scales of most-active contributors}

Table $\mathrm{X}$ shows the correlation matrix of the most-active students for 5 motivational subscales of intrinsic goal orientation, extrinsic goal orientation, task value, control of learning beliefs, self- efficacy for learning and performance. As tabulated in the table, the most-active (MA) students' intrinsic goal orientation was positively correlated with their perception of task value $(r=.701, p<0.01)$, with the strongest correlation ( $\mathrm{r}$ value $>.70$ ). Their self-efficacy for learning and performance was also positively correlated with their perception of task value with a moderate correlation $(r=.485$, $p<0.05)$, and students' control of learning beliefs with $(r=.492$, $p<0.05)$. Statistic shows a moderate correlation with a value of $(.3<r<.69)$ between the two.

TABLE X: RELATIONSHIPS BETWEEN MOTIVATION SUB-SCALES OF MOST-ACTIVE CONTRIBUTORS

\begin{tabular}{llllll}
\hline Variables & Intrinsic & Extrinsic & $\begin{array}{l}\text { Task } \\
\text { Value }\end{array}$ & Control & Self-efficacy \\
\hline Intrinsic & 1 & .220 & $.701^{* * *}$ & .259 & .432 \\
Extrinsic & .220 & 1 & .008 & .144 & .155 \\
Task Value & $.701^{* *}$ & .008 & 1 & .410 & $.485^{*}$ \\
Control & .259 & .144 & .410 & 1 & $.492^{*}$ \\
Self-efficacy & .432 & .155 & $.485^{*}$ & $.492^{*}$ & 1 \\
\hline \hline & **. Correlation is significant at the 0.01 level (2-tailed). \\
*. Correlation is significant at the 0.05 level (2-tailed).
\end{tabular}

The finding reveals that the strongest correlation of motivational components for the active-contributors is intrinsic goal orientation and perception of task value. This suggests that the students who make most contribution (MA) to the question-generation activity generally have, both, high level of intrinsic goal orientation and high perception of task value.

\section{2) Relationship between motivation sub-scales of least-active contributors}

Results in Table XI shows the correlation matrix of the least-active students for 5 motivational subscales of intrinsic goal orientation, extrinsic goal orientation, task value, control of learning beliefs, self- efficacy for learning and performance. The analysis reveals that the least-active (LA) students' intrinsic goal orientation was positively correlated with their extrinsic motivation $(r=.390, p<0.05)$, shows that least active students' intrinsic goal orientation are interconnected with their extrinsic goal orientation, with a moderate correlation of $(.3<r<.69)$. Also, the least-active students' self-efficacy for learning and performance was also positively correlated with their perception of task value with a correlation of $(r=.403$, $p<0.05)$, and students' control of learning beliefs with $(r=.365$, 
$p<0.05)$. Both subscales too, show a moderate correlation with a value of $(.3<r<.69)$.

The result reveals that least active students have a moderate correlation between the motivational components of intrinsic and extrinsic goal orientation, students' self-efficacy for learning and performance and their perception of task value; and also, between least-active students' self-efficacy for learning and performance and their control of learning beliefs.

TABLE XI: RELATIONSHIP BETWEEN MOTIVATION SUB-SCALES OF LEAST-ACTIVE CONTRIBUTORS

\begin{tabular}{llllll}
\hline \multicolumn{5}{c}{ LEAST-ACTIVE CONTRIBUTORS } \\
\hline Variables & ntrinsic & Extrinsic & $\begin{array}{l}\text { Task } \\
\text { Value }\end{array}$ & Control & Self-efficacy \\
\hline Intrinsic & 1 & $.390^{*}$ & -.296 & .161 & .122 \\
Extrinsic & $.390^{*}$ & 1 & -.179 & .173 & .271 \\
Task & -.296 & -.179 & 1 & .184 & $.403^{*}$ \\
Value & .161 & .173 & .184 & 1 & $.365^{*}$ \\
Control & .122 & .271 & $.403^{*}$ & $.365^{*}$ & 1 \\
Self-efficac & .122 & &
\end{tabular}

In short, the motivational components with statistically significant differences between most-active and least-active contributors are: intrinsic goal orientation, task value and control of learning beliefs. The motivational components were then look into per item.

Generally, the correlation shows that students' who are high in intrinsic motivation (the most-active contributors), have high perception of task value; whereby, they feel that the task given, which is to create, share and answer multiple-choice online as important and beneficial. To compare with the least-active contributors, from the correlation analysis performed, it can be seen that there are moderate correlation between intrinsic goal orientation and extrinsic goal orientation. The finding may suggest that, for least active contributors, their intrinsic goal orientation is dependent with their extrinsic goal orientation.

\section{DISCUSSION}

\section{A. Summary of Student Involvement in the Question-Generation Activity}

From the data, two very clear pattern of engagement are noticeable. Students in both categories, most active and least-active, have authored more questions, on average, than required. However, students in the most-active categories have answered far more than required, with an average of 15.8, as compared to the least-active categories, which they have answered less than the required number.

The distribution of question contribution by the students shows that no students have contributed more than 2 questions, even from the most-active categories.

\section{1) Question authoring}

From the data obtained from PeerWise, an online tool where students engage with the question authoring and answering activity, analysis shows that none of the students have authored more than 2 questions during the activity.

Suggested in the literature, students who are able to create their own multiple-choice questions will generally do better than just attempting to answer teacher-provided questions; as they help to nurture critical thinking [32], and encouraging self-directed learning, [30]. However, authoring multiple-choice questions is not a simple task, it takes a lot of effort as students would have to generate an appropriate question stem, and then come up with a number of suitable alternatives that contain several distractors. The generation of alternatives will probably be the most challenging; as it is not an easy task to create a few distractors that are close to the answer without disclosing the correct answer. Students who are involved in this study has never been involved in question-generation activity before, thus authoring own multiple-choice questions may be a demanding task for them. Therefore, this may be one of the factors that discourage students in authoring more multiple-choice questions than required.

\section{2) Question answering}

During the activity of authoring and answering questions, based on the distribution of question answered, in general, $32.1 \%$ answered less than the required number, which is 5 questions, the majority $(57.2 \%)$ answered in the range of 5 to 20 questions. The remaining $3.6 \%$ and $7.1 \%$ answered in the range of 21-40 questions and more than 40 questions respectively. However, most of the students who contributed in the question answering through PeerWise are the most-active students as on average, the least-active students contributed less than the required number of questions. Further analysis performed on most-active and least-active students, looking at their motivational drive reveals that, least-active students are lack in internal motivation as compared to the most-active students.

The reduced quantity of question answered by the least-active students may be inferred as low intrinsic goal orientation, considering that there is no external motivation, in terms of extra marks or constant reminders by teachers was offered to the students. A study done by [21] involving students authoring and answering own multiple-choice questions, reveals that students' require external motivation in terms of reminder or marks to support students' question-generation.

\section{B. Differences between Motivation on Active and Least Active Contributors}

Findings from the analysis reveal that there were significant differences between most-active and least-active contributors in the component of intrinsic goal orientation, task value, and control of learning beliefs.

The findings also indicated that most-active contributors have higher intrinsic goal orientation, task value orientation and control of learning beliefs as compared to least-active contributors of question generation activity. The least-active contributors are not actively engage in the activity probably because they have weakened intrinsic goal orientation due to the absence of extrinsic motivators [15] such as teachers' reminder or marks.

The analysis performed in this study further revealed that the participants who are most-active contributors are inspired to participate in the question-generation activity primarily from internal reasons such as being curious, wanting to take up challenge, and wanting to master the content. They also have the tendency to prefer materials that are challenging instead of straightforward and simple where they could learn more from; which have resulted and promote active 
engagement in the question generation activities. The other motivational construct such as extrinsic goal orientation and self-efficacy shows no difference between most-active and least-active students.

In terms of students' perception of task value, most-active students positively viewed the importance of course materials whereby they believed that the materials were useful, interesting and that they could apply what they have learned from the activity in other courses. Moreover, active contributors of the question-generation activity are also certain that the outcome of their learning, whether successful or not, are totally depending on their effort. This portray meaningful outcomes as a study by [43] has indicated that students that have high control of learning beliefs; whereby, when they believe that the success of their learning is influenced mostly by their actions and effort in studying, they usually have the tendency to study more effectively.

\section{Relationship between Motivation Components and} Students' Engagement in the Question-Generation Activity

The matrix correlation shows that students' who are high in intrinsic motivation, which are the most-active contributors, have high perception of task value; where, they feel that the task given, which is to create, share and answer multiple-choice online as important and beneficial. This can be supported by a study by [39] claims that intrinsic motivation is a powerful drive in encouraging learners to contribute to the learning process without the guidance and direction of the teaching staff

To compare with the least-active contributors, from the correlation analysis performed, it can be seen that there are moderate correlation between intrinsic goal orientation and extrinsic goal orientation. The finding may suggest that, for least active contributors, their intrinsic goal orientation is dependent with their extrinsic goal orientation; which most probably the cause of less participation in the question-generation activity as no marks, grades, or teachers evaluation are present during the engagement with this activity. For the reason of reducing any possible distractor, of especially extrinsic motivational elements, no marks were allocated for students participating in the activity; as well as, only minimal guidance from teacher are provided and academic staff involvement was passive after introducing and guiding them to write their own multiple choice question in the second week of the class.

The finding can be further supported by a study by [38], as they revealed that students' motivation change from course to course, depending on factors such as; their interest in the course, efficacy for performing in a course, their goals or even the value beliefs they have for the particular course. It is perceived that students with higher motivation level in learning would generally perform better, has higher involvement and were more efficient in performing task given; that therefore, will lead to them achieving better grades than those who are less motivated in their study. From the correlation analysis performed, it is evident that, students who contribute and engage actively with the question generation activity, without expecting any external drive such as rewards, marks, grades or compliment from teachers are those with strong intrinsic motivation drive.

\section{LIMITATION OF THE STUDY}

The limitation of this study that could have affected the result is the maturation of the respondents, where older students would generally have developed more skills and have better orientation as compared to younger respondents. The course content could also affect the result of the study as different course materials would have different level of difficulty.

Another limitation is whether the result are able to be generalised to other populations of learners since the sample used is rather small in size and most of the students who participated in this study are mostly females; since females and male usually have different learning styles and goals.

\section{CONCLUSION}

Technological innovations can contribute to the growth of learners' interest and motivation; provide students with interaction opportunities and feedback, as the new generation of web 2.0 technologies are able to facilitate online class collaboration and allow students to create and share content in a variety of forms [12] and further allowing students to be actively engaged and in control of their learning process [13]. However, recent evidence indicates that by paying insufficient attention to motivation, even high-cognitive activities such as problem-based learning might not be able to boost learning among students [2]. Therefore, this study has intended to look into the effects of engaging students in question-generation activities have on their learning motivation.

After collecting data and analysing the results, findings shows that students who contribute and engage actively without expecting any external motivation, with the question-generation activity, are those with strong intrinsic motivation drive. To support the findings of this current study, many studies conducted has also clearly evidenced that one of the principal determinant of success in learning is motivational factor [1].

In short, the result of this study indicates that students who are highly engaged in question-generation activities have strong motivational drive, especially high in intrinsic goal orientation, task value orientation and control of learning beliefs as compared to those that are not actively engage in the activity as, they probably have weakened intrinsic goal orientation due to the absence of extrinsic motivators [15] such as teachers' reminder or marks.

\section{REFERENCES}

[1] R. Stoffa, J. C. Kush, and M. Heo, "Using the motivated strategies for learning questionnaire and the strategy inventory for language learning in assessing motivation and learning strategies of generation 1.5 Korean immigrant students," Education Research International, 2011

[2] B. R. Belland, C. Kim, and M. J. Hannafin, "A framework for designing scaffolds that improve motivation and cognition," Educational Psychologist, vol. 48, no. 4, pp. 243-270, 2013.

[3] C. McLoughlin and M. J. Lee, "Personalised and self-regulated learning in the Web 2.0 era: International exemplars of innovative pedagogy sing social software," Australasian Journal of Educational Technology, vol. 26, no. 1, 2010.

[4] F. Y. Yu and C. P. Wu, "Predictive effects of online peer feedback types on performance quality," Educational Technology \& Society, vol. 16, no. 1, pp. 332-341, 2013 
[5] L. Singh, "Technology enhanced peer learning with PeerWise: Experiences and perception from a developing country," Caribbean Teaching Scholar, vol. 4, no. 1, pp. 5-22, 2014.

[6] S. Bottomley and P. Denny, "A participatory learning approach in biochemistry using student authored and evaluated multiple-choice questions," Biochemistry and Molecular Biology Education, vol. 39, no. 5, pp. 352-361, 2011

[7] P. Denny et al., "PeerWise Students sharing their multiple choice questions," in Proc. the Fourth International Workshop on Computing Education Research, 2008, pp. 51-58.

[8] V. Kalloo and P. Mohan, "Correlation between student performance and use of an mLearning application for high school mathematics," in Proc. 2011 11th IEEE International Conference on Advanced Learning Technologies, 2011, pp. 174-178.

[9] L. Singh. (2013). Guided assessment or open discourse: A comparative analysis of students' interactions on Facebook groups. Turkish Online Journal of Distance Education. [Online]. 14(1). pp. 35-43. Available: http://dergipark.ulakbim.gov.tr/tojde/article/view/5000102174

[10] L. Singh and K. Gaffar, "Using social software to support computer science education: A case of using Facebook group," E-Journal of the Caribbean Academy of Science, vol. 5, no. 1, pp. 2188-2260, 2011.

[11] L. Singh, K. Gaffar, and T. D. Thomas, "Mobile learning: Lecturers versus students on usage and perception using UTAUT," presented at $2^{\text {nd }}$ Int. Scientific Conf. University of Technology Jamaica, 2012.

[12] L. Hakulinen and A. Korhonen, "Making the most if using PeerWise in education," in Proc. ReflekTori 2010 Symposium of Engineering Education, 2010, p. 57.

[13] P. Ramsden, Learning to Teach in Higher Education, London: Routledge Falmer, 2003.

[14] J. Hamer, Q. Cutts, J. Jackova, A. Luxton-Reilly, R. McCartney, H. Purchase, and J. Sheard, "Contributing student pedagogy," ACM SIGCSE Bulletin, vol. 40, no. 4, pp. 194-212, 2008.

[15] D. H. Pink, Drive: The Surprising Truth about What Motivates Us, New York: Riverhead Trade, 2011.

[16] P. C. Blumenfeld, T. M. Kepler, and J. S. Krajcik, "Motivation and cognitive engagement in learning environments," in The Cambridge Handbook of the Learning Science, R. K. Sawyer, Ed. New York: Cambridge University Press, 2006.

[17] S. A. Parsons and A. E. Ward, "The case for authentic tasks in content literacy," The Reading Teacher, vol. 64, no. 6, pp. 462-465, 2011.

[18] P. C. Blumenfeld, E. Soloway, R. W. Marx, J. S. Krajcik, M. Guzdial, and A. Palincsar, "Motivating project-based learning: Sustaining the doing, supporting the learning," Educational Psychologist, vol. 26, no. 3, pp. 369-398, 1991.

[19] D. H. Dolmans and H. G. Schmidt, "What do we know about cognitive and motivational effects of small group tutorials in problem-based learning?" Advances in Health Sciences Education, vol. 11, no. 4, pp. 321-336, 2006

[20] D. Hung, "Design principles for web-based learning: Implications from Vygotskian thought," Educational Technology, vol. 41, no. 3, pp. $33-41,2001$.

[21] P. Denny, A. Luxton-Reilly, and J. Hamer, "The PeerWise system of student contributed assessment questions," in Proc. the Tenth Conf. on Australasian Computing Education ACE, 2008, vol. 78, pp. 69-74.

[22] L. Hakulinen, "Using computer supported cooperative work systems in computer science education - Case: PeerWise at TKK," M.S. thesis, Faculty of Information and Natural Science, School of Science and Technology, Aalto University, Finland, 2010.

[23] J. H. Paterson, J. Devon, J. McCrae, and E. Gray, "Enhancing the quality of student-generate," MCQ's: A Final Report, 2011.

[24] S. P. Bates, R. K. Galloway, and K. L. McBride, "Student generated content using PeerWise to enhance engagement and outcomes in introductory physics courses," in Proc. the 2011 Physics Education Research Conference, 2011, pp. 123-126.

[25] C. Chin and D. E. Brown, "Student-generated questions: A meaningful aspect of learning in science," International Journal of Science Education, vol. 24, no. 5, pp. 521-549, 2002.

[26] P. Baty, "Class is allowed to set exam," Times Higher Education Supplement, June 2006.

[27] B. Rosenshine, C. Mesiter, and S. Chapman, "Teaching students to generate questions: A review of the intervention studies," Review of Educational Psychology, vol. 66, no. 2, pp. 181-221, 1996.

[28] A. Palinscar and A. Brown, "Reciprocal teaching of comprehension-fostering and comprehension-monitoring activities," Cognition \& Instruction, vol. 2, pp. 117-175, 1984.

[29] S. W. Draper, "Catalytic assessment: Understanding how MCQs and EVS can foster deep learning," British Journal of Educational Technology, vol. 40, no. 2, pp. 285-293, 2009.
[30] D. Nicol, "E-assessment by design: Using multiple choice tests to good effect," Journal of Further and Higher Education, vol. 31, no. 1, pp. 53-64, 2007.

[31] J. Hardy, S. P. Bates, M. M. Casey et al., "Student-generated content: Enhancing learning through sharing multiple-choice questions," International Journal of Science Education, vol. 36, no. 13, pp. 2180-2194, 2014.

[32] L. G. Herman, "Designing contributing student pedagogies to promote student's intrinsic motivation to learn," Computer Science Education, vol. 22, no. 4, pp. 369-388, 2012.

[33] P. Denny, B. Hanks, and B. Simon, "PeerWise: Replication study of a student-collaborative self-testing web service in a U.S setting," in Proc. the $41^{\text {st }}$ ACM Technical Symposium on Computer Science Education, pp. 421-425, 2010

[34] H. Ajjan and R. Hartshorne, "Investigating faculty decision to adopt web 2.0 technologies: Theory and empiric test," Internet and Higher Education, vol. 11, pp. 71-80, 2008.

[35] G. Gay, S. Mahon, D. Devonish, D. Alleyne, and P. Alleyne, "Perceptions of information and communication technology among undergraduate management students in Barbados," International Journal of Education and Development Using ICT, vol. 2, no. 4, 2006

[36] R. M. Marra and T. Wheeler, "The impact of an authentic, student-centered engineering project on student motivation," in Proc. 30th Annual Frontiers in Education Conference, 2000, vol. 2, pp. F2C-8

[37] M. B. Paulsen and J. A. Gentry, "Motivation learning strategies and academic performance: A study of the college finance classroom," Financial Practice and Education, vol. 5, no. 1, pp. 78-89, 1995.

[38] P. R. Pintrich, D. A. Smith, T. García, and W. J. McKeachie, "Reliability and predictive validity of the motivated strategies for learning questionnaire (MSLQ)," Educational and Psychological Measurement, vol. 53, no. 3, pp. 801-813, 1993.

[39] B. Collis and J. Moonen, "The contributing student: The learner as co-developers of learning resource for reuse in web environment," in Engaged Learning with Emerging Technologies, D. Hung and M. S. Khine, Eds. Dordrecht, The Netherlands: Springer, 2006.

[40] A. R. Artino Jr. and J. M. Stephen, "Academic motivation and self-regulation: A comparative analysis of undergraduate and graduate students learning online," Internet and Higher Education, vol. 12, pp. 146-151, 2009.

[41] C. Ames, "Classrooms: Goals, structure and student motivation," Journal of Educational Psychology, vol. 84, no. 3, pp. 261-271, 1992

[42] I. Mitchell and A. Carbone, "A typology of task characteristics and their effects on student engagement," International Journal of Educational Research, vol. 50, no. 5, pp. 257-270, 2011.

[43] P. R. Pintrich, D. A. F. Smith, T. Garcia, and W. J. McKeachie. A Manual for the Use of the Motivated Strategies for Learning Questionnaire (MSLQ), Ann Arbor: University of Michigan, 1991.

[44] R. K. Gable and M. B. Wolf, Instrument Development in the Affective Domain, Springer Science \& Business Media, vol. 36, 1993.

Masturah Sabri was born in Kedah, Malaysia on July 26, 1989. She received her B.Ed. degree in teaching English as a second language (TESL) in 2011. She then obtained her M.A degree of similar field, from Universiti Kebangsaan Malaysia, in 2015.

She is currently a lecturer at the Centre for International Languages, Universiti Malaysia Perlis (UniMAP), Perlis, Malaysia. Her research interes includes teaching methodologies and learning styles.

Faten Khalida Khalid was born in Alor Setar, Kedah on October 20, 1988 She is a language teacher at the Centre for International Languages, Universiti Malaysia Perlis (UniMAP).

She obtained her B.HSc (Hons.) degree in English language and literature from Universiti Islam Antarabangsa Malaysia (UIAM) in 2012. She is currently doing her master's degree in applied linguistics in Universiti Utara Malaysia (UUM). Her research interest is in pedagogy, sociolinguistics, psycholinguistics and materials development in language teaching.

Liew Khe Li was born in Kedah, Malaysia. She had graduated from Universiti Utara Malaysia with a master's degree in applied linguistics in 2011. She obtained her bachelor's degree in education (TESL) from Universiti Malaya in 2009.

She is a lecturer of the Centre for International Languages, Universiti Malaysia Perlis (UniMAP). Her research interest includes ESP, applied linguistics, language teaching and learning and cross-cultural communication. 